\title{
Pemodelan Integer Linear Programming pada Penjadwalan Produksi Tipe Flowshop dan Program Optimasi Waktu dengan Metode Branch And Bound Studi Kasus: PT UNITEX
}

\author{
Ismawati Khotimah $^{1, \text { a) }}$, Hagni Wijayanti ${ }^{1, b)}$, Sri Setyaningsih ${ }^{1, c)}$ \\ ${ }^{1}$ Program Studi Matematika, Fakultas Matematika dan Ilmu Pengetahuan Alam, Universitas Pakuan, Bogor \\ Email : ${ }^{a}$ ismawatikhotimah@gmail.com, b)hagnijantix@unpak.ac.id
}

\begin{abstract}
Scheduling is the allocation of the available resources to complete a number of jobs by considering the restrictions. It is quite important for company to determine the optimal scheduling so that the production process run smoothly, efficiently, and systematically. PT Unitex is one of the textil company. The scheduling in this company was inefficient and caused some problems, such as the time to complete the production was missed due to the uncertainty of consumer demands. The scheduling in this company was based on estimation, not using scientific methods. Branch and Bound method can be implemented to the company because this method can determine the optimal scheduling for the company. By using this method, we can find an optimal solution of scheduling by determining the upper bound value and lower bound value to obtain the makespan value for each job. The result of the scheduling by this method is that the order of production process should be 1-5-3-6-7-2-4 with makespan 17290.73 minutes. It is smaller that the company makespan, which was 19278.13 minutes. So, it minimized the makespan by $10.31 \%$.
\end{abstract}

Keywords: scheduling, branch and bound, makespan.

\begin{abstract}
Abstrak
Penjadwalan merupakan pengalokasian sumber daya yang tersedia untuk menyelesaikan sejumlah pekerjaan dengan mempertimbangkan batasan yang ada. Hal yang cukup penting dalam perusahaan adalah menentukan penjadwalan yang optimal agar kegiatan produksi dapat berjalan dengan lancar, efisien, dan sistematis. PT Unitex merupakan perusahaan yang bergerak dalam bidang tekstil. Perusahaan ini menerapkan penjadwalan yang kurang efisien sehingga menyebabkan permasalahan seperti keterlambatan waktu dalam penyelesaian produksi akibat terlalu banyaknya permintaan konsumen yang tidak menentu. Perusahaan melakukan penjadwalan hanya diperkirakan saja dan tidak menggunakan metode ilmiah. Metode Branch and Bound dapat diterapkan pada permasalahan tersebut karena dapat menentukan penjadwalan yang tepat dengan waktu optimal. Metode Branch and Bound adalah metode pencarian dalam menentukan solusi optimal pada penjadwalan dengan menentukan nilai batas atas dan nilai batas bawah untuk menghasilkan nilai makespan dari tiap job yang dikerjakan. Penjadwalan menggunakan Metode Branch and Bound menghasilkan urutan penjadwalan produksi dengan job 1-5-36-7-2-4 dengan makespan sebesar 17290.73 menit. Nilai ini lebih kecil dibandingkan hasil makespan perusahaan yaitu 19278.13 menit. Hal tersebut meminimumkan makespan sebesar $10.31 \%$.
\end{abstract}

Kata kunci: penjadwalan, branch and bound, makespan.

Diterima: 14 Februari 2020, Direvisi: 31 Januari 2021, Disetujui: 31 Januari 2021 


\section{PENDAHULUAN}

\section{Latar Belakang}

Semakin ketatnya persaingan di dunia bisnis mengakibatkan meningkatnya kebutuhan pada produksi yang efisien dan efektif pada perusahaan. Salah satu strategi utamanya adalah memenuhi kebutuhan konsumen secara tepat dalam sisi waktu serta kualitas produk yang baik. Oleh karena itu, perusahaan perlu melakukan penjadwalan yang baik dalam menjalankan proses produksinya. Menurut Baker and Trietsch (2009), penjadwalan merupakan suatu aktivitas urutan pekerjaan yang dialokasikan berdasarkan sumber daya yang ada agar tercapainya tujuan dan sasaran yang lebih optimal.

Penjadwalan produksi pada PT UNITEX yang kurang efisien menyebabkan permasalahan seperti keterlambatan waktu dalam penyelesaian produksi akibat terlalu banyaknya permintaan konsumen yang tidak menentu. Menghadapi hal ini perusahaan melakukan penjadwalan hanya mengunakan perkiraan saja dan tidak menggunakan metode ilmiah. Melihat kondisi tersebut, maka diperlukan adanya penjadwalan produksi yang tepat.

Metode Branch and Bound dapat diterapkan pada permasalahan tersebut karena dapat menentukan penjadwalan yang tepat dengan waktu optimal. Metode Branch and Bound merupakan suatu prosedur yang paling umum untuk mencari solusi optimal pada masalah optimasi pada penjadwalan tersebut.

\section{Tujuan}

Berdasarkan latar belakang yang ada, maka tujuan dalam penelitian ini yang diharapkan adalah sebagai berikut.

1. Membangun model Integer Linear Programming pada penjadwalan produksi.

2. Implementasi Algoritma Branch and Bound pada penjadwalan produksi tipe flowshop.

3. Membuat program penjadwalan untuk mengoptimalkan produksi pada PT UNITEX.

4. Membandingkan penjadwalan yang ditentukan oleh perusahaan dengan hasil penelitian berupa penjadwalan menggunakan metode Branch and Bound dengan melihat waktu penjadwalan yang optimal.

\section{METODOLOGI PENELITIAN}

\section{Pengumpulan Data}

Data yang digunakan dalam penelitian ini adalah data primer berupa hasil wawancara terhadap pihak perusahaan mengenai waktu proses produksi, serta data sekunder yang meliputi data rencana produksi kain pada PT UNITEX bulan Desember 2018.

\section{Tahapan Analisis}

Penelitian ini memiliki rangkaian tahapan analisis yaitu:

1. Mengumpulkan data yang akan digunakan untuk menghitung waktu proses produksi di PT UNITEX. Pada penelitian ini data yang digunakan adalah data rencana produksi kain pada bulan Desember 2018.

2. Menghitung waktu proses produksi dalam setiap job pada setiap mesin yang tersedia berdasarkan data rencana kerja yang diperoleh dan perhitungan yang telah ditetapkan oleh perusahaan.

3. Membangun model matematika pada penjadwalan produksi tipe flowshop berdasarkan batasanbatasan yang ada. Model matematika ini dibangun untuk menentukan penjadwalan produksi yang optimal dengan nilai makespan yang minimum

4. Menentukan penjadwalan yang optimal berdasarkan model yang telah dibangun pada tahap ketiga. Penentuan penjadwalan yang optimal menggunakan bantuan software LINGO 11.0.

5. Menyelesaikan Algoritma Branch and Bound pada penjadwalan produksi. Berdasarkan algoritma tersebut terdapat langkah-langah perhitungan yaitu menghitung waktu proses setiap job di masingmasing mesin, serta menentukan nilai batas bawah untuk mengetahui job yang akan dijadwalkan terlebih dahulu, selanjutnya menentukan total waktu penyelesaian (completion time) pada job di 
masing-masing mesin hingga lintasan terakhir, menghitung nilai waktu proses produksi pada tiap mesin dan nilai batas menggunakan Algoritma Branch and Bound, membandingkan semua nilai batas dan memilih nilai paling maksimum pada setiap job. Selanjutnya, batas bawah/lower bound diambil sebagai nilai minimum. Job dengan nilai batas bawah terrendah akan dijadwalkan terlebih dahulu. Setelah itu job tersebut dihilangkan dari daftar dan langkah diulangi sampai semua pekerjaan dijadwalkan.

6. Implementasi metode Branch and Bound dalam program aplikasinya yang akan dibuat syntax pemrograman untuk penyelesaian metode Branch and Bound agar dapat memudahkan perusahaan dalam menentukan penjadwalan yang optimal.

7. Interpretasi hasil yang diperoleh dari penjadwalan dengan urutan job dan nilai makespan yang paling optimal dan membandingkan penjadwalan usulan dengan penjadwalan pada perusahaan.

\section{HASIL DAN PEMBAHASAN}

\section{Waktu Proses Produksi}

Rencana produksi pada PT UNITEX dalam pembuatan kain berdasarkan permintaan konsumen yang telah ditentukan waktu produksi berdasarkan perhitungan perusahaan dalam setiap mesinnya. Terdapat 7 job yang diproses dalam 6 mesin. Perhitungan waktu proses produksi yang telah diperoleh adalah sebagai berikut.

TABEL 1. Perhitungan Waktu Proses Produksi

\begin{tabular}{cccccccc}
\hline Job & Desain & Kowari & Warper & Sizing & Reaching & Shokki & Shiage \\
\hline 1 & PKF/01/12 & 145.75 & 3.89 & 58.30 & 233.20 & 9.72 & 43.73 \\
2 & SOLID & 511.00 & 15.90 & 238.47 & 4435.48 & 39.74 & 178.85 \\
3 & SOLID & 170.71 & 5.31 & 79.67 & 496.59 & 13.28 & 59.75 \\
4 & HYO/047 & 1091.92 & 29.12 & 436.77 & 10613.43 & 72.79 & 327.58 \\
5 & PKF/P20/09 & 161.79 & 5.03 & 75.50 & 447.97 & 12.58 & 56.63 \\
6 & PKF/P24/09 & 265.58 & 7.08 & 106.23 & 888.82 & 17.71 & 79.68 \\
7 & PKL/26/09 & 332.25 & 8.86 & 132.90 & 1391.02 & 22.15 & 99.68 \\
\hline
\end{tabular}

Berdasarkan Tabel 1, dapat diketahui bahwa setiap job yang diproses di berbagai mesin menghasilkan waktu proses yang berbeda-beda. Hasilnya dapat dilihat pada Gambar 1 yang digambarkan berdasarkan Gantt Chart perhitungan perusahaan.

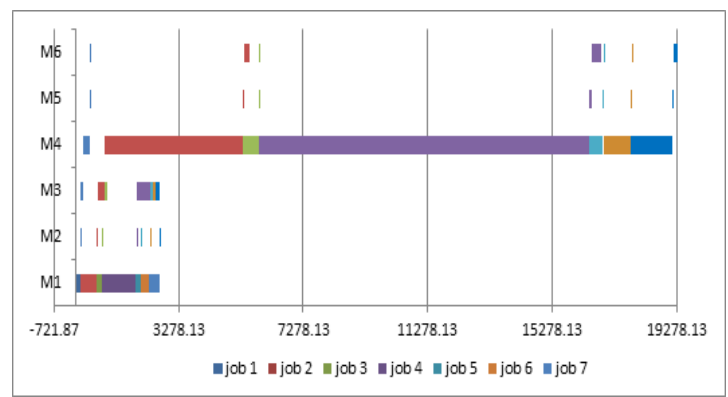

GAMBAR 1. Gantt Chart Perusahaan

Berdasarkan Gantt Chart yang telah digambarkan, job yang telah selesai diproses pada mesin sebelumnya akan langsung diproses pada mesin selanjutnya, sehingga dapat diketahui bahwa total waktu penyelesaian seluruh job yaitu 19278.13 menit dengan urutan penjadwalan perusahaan yaitu job 1-2-3-4-5-6-7. 


\section{Waktu Setup Produksi}

Waktu setup dalam produksi merupakan waktu persiapan yang dibutuhkan pada setiap pekerjaan untuk melakukan operasi atau proses di setiap mesin. Waktu setup dapat dilihat pada Tabel 2 sebagai berikut. Namun, untuk mempermudah dalam proses penulisan syntax model Integer Linear Programing, maka akan disusun matriks waktu setup setiap job yang dapat dilihat pada Tabel 3.

TABEL 2. Waktu Setup Produksi (menit)

\begin{tabular}{cc}
\hline Job & Waktu setup \\
\hline 1 & 874.8 \\
2 & 739.2 \\
3 & 790.8 \\
4 & 1102.2 \\
5 & 787.2 \\
6 & 786 \\
7 & 786 \\
\hline
\end{tabular}

TABEL 3. Matriks Waktu Setup Produksi (menit)

\begin{tabular}{ccccccccc}
\hline \multicolumn{7}{c}{} & \multicolumn{7}{c}{ Job $(\boldsymbol{j})$} \\
\hline & $\mathbf{1}$ & $\mathbf{1}$ & $\mathbf{2}$ & $\mathbf{3}$ & $\mathbf{4}$ & $\mathbf{5}$ & $\mathbf{6}$ & $\mathbf{7}$ \\
\hline & $\mathbf{2}$ & 1674.8 & 1692 & 1689.6 & 2001 & 1686 & 1684.8 & 1684.8 \\
Job $(\boldsymbol{k})$ & $\mathbf{3}$ & 1689.6 & 1584 & 790 & 1893 & 1578 & 1576.8 & 1576.8 \\
& $\mathbf{4}$ & 2001 & 1895.4 & 1893 & 1102.2 & 1889.4 & 1888.2 & 1888.2 \\
& $\mathbf{5}$ & 1686 & 1580.4 & 1578 & 1889.4 & 787.2 & 1573.2 & 1573.2 \\
& $\mathbf{6}$ & 1684.8 & 1579.2 & 1576.8 & 1888.2 & 1573.2 & 786 & 1572 \\
& $\mathbf{7}$ & 1684.8 & 1579.2 & 1576.8 & 1888.2 & 1573.2 & 1672 & 786 \\
\hline
\end{tabular}

Pada Tabel 3 dijelaskan mengenai hubungan antara job j dan job k. Job j merupakan job yang akan dikerjakan terlebih dahulu dari job k. Nilai yang didapat dari hubungan antar job merupakan nilai waktu setup $(S(j, k))$. Jika pengambilan job j dan job k merupakan job yang sama, maka nilai waktu setup dari data pada Tabel 3 adalah tetap. Namun, jika pengambilan job j dan job k merupakan job yang berbeda, maka kedua job tersebut dijumlahkan untuk memperoleh nilai waktu setup $(S(j, k))$.

\section{Model Integer Linear Programming}

1. Total waktu penyelesaian pada suatu pekerjaan untuk masing-masing mesin.

$$
C_{\max } \geq C(i, j) \forall_{k} \in\{1,2, \ldots, 7\}
$$

2. Selisih waktu penyelesaian antara satu job dengan job sebelumnya tidak kurang dari jumlah waktu proses dengan waktu setup.

$$
\begin{gathered}
C(i, k)-C(i, j)+M\left(1-(X(i, j, k)) \geq S(j, k)+P(k), \forall_{j} \in\{1,2, \ldots, 7\}, \forall_{k} \in\right. \\
\{1,2, \ldots, 7\}, j \neq k, \forall_{i} \in\{1,2, \ldots 6\}
\end{gathered}
$$

Untuk nilai waktu setup $S(j, k)$ dapat dilihat pada Tabel 4 dan untuk nilai waktu proses produksi dapat dilihat pada tabel berikut.

TABEL 4. Waktu Proses Produksi (menit)

\begin{tabular}{|c|c|}
\hline Job & Nilai \\
\hline 1 & 494.58 \\
\hline 2 & 5419.44 \\
\hline 3 & 825.31 \\
\hline
\end{tabular}




\begin{tabular}{|c|c|}
\hline Job & Nilai \\
\hline 4 & 12571.6 \\
\hline 5 & 759.49 \\
\hline 6 & 1365.1 \\
\hline 7 & 1986.86 \\
\hline
\end{tabular}

3. Hanya terdapat satu job $\mathrm{j}$ yang boleh mendahului $j o b \mathrm{k}$

4. Hanya terdapat satu job $\mathrm{k}$ yang dikerjakan secara langsung setelah job $\mathrm{j}$.

$$
\sum_{j}^{7} \sum_{i}^{6} X(i, j, k)=1, j \neq k
$$

5. Masing-masing job hanya dikerjakan satu kali di satu mesin.

$$
X(i, j, k)=0, \forall_{j} \in\{1,2, \ldots, 7\}, \forall_{k} \in\{1,2, \ldots, 7\}, \forall_{i} \in\{1,2, \ldots, 6\}, j=k
$$

6. Masing-masing job hanya dikerjakan di satu mesin.

$$
\sum_{i}^{6} \sum_{j}^{7} \sum_{k}^{7} X(i, j, k) \leq 1, j \neq k
$$

\section{Aplikasi Model Integer Linear Programming Menggunakan LINGO}

Permasalahan dalam menentukan penjadwalan produksi pada 7 job dengan melewati proses 6 mesin dapat diselesaikan secara komputasi dengan menggunakan bantuan software LINGO 11.0. Pada Gambar 2 berikut merupakan hasil output pada LINGO 11.0.

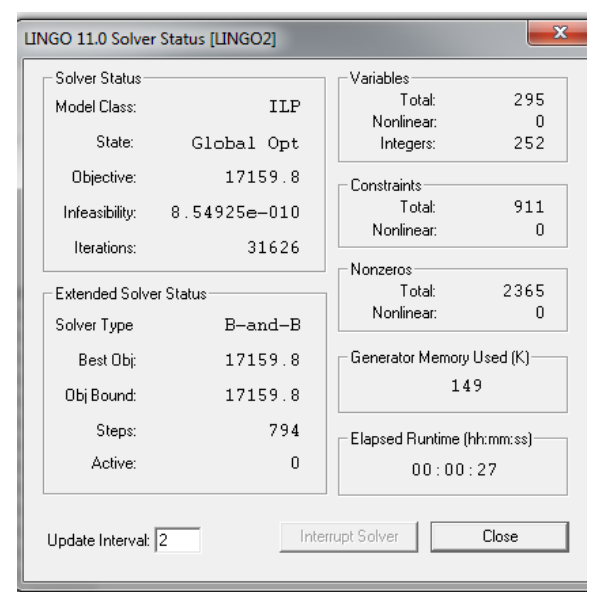

GAMBAR 2. Solver Status LINGO 11.0

Dari Gambar 2 tersebut, dapat diketahui bahwa total variabel yang terdapat pada model Integer Linear Programming adalah 295 variabel dengan total batasan sebesar 911, nonzeros sebesar 2365 koefisien. Dengan total variabel, batasan, dan koefisien tersebut, diperoleh iterasi sebesar 31626 iterasi.

Oleh karena itu, nilai fungsi objektif pada waktu pengerjaan seluruh job/makespan sebesar 17159.8 menit. 
Pemodelan Integer Linear Programming pada Penjadwalan Produksi Tipe Flowshop dan Program Optimasi ...

\section{Metode Branch and Bound}

Adapun untuk menyelesaikan perhitungan penjadwalan dengan Metode Branch and Bound, terdapat beberapa iterasi yang perlu diselesaikan. Untuk algoritmanya dapat diformulasikan sebagai berikut.

$$
b_{j i}=q_{j i}+\sum_{j \notin j \prime}, t_{j i}+\min _{j \notin j \prime}\left(\sum_{i \notin i}, t_{j i}\right)
$$

Selanjutnya batas bawah ditentukan dengan formula sebagai berikut.

Keterangan:

$$
B=\max \left(b_{1}, b_{2}, \ldots, b_{7}\right)
$$

$b_{j i}:$ Nilai batas job pada mesin

$q_{j i}:$ Waktu penyelesaian job pada tiap mesin

$t_{j i}$ : Waktu proses untuk job pada mesin

B : Nilai maksimum atau nilai batas atas

Berikut merupakan tabel hasil perhitungan pada Metode Branch and Bound dengan masing-masing iterasi.

TABEL 5. Perhitungan Branch and Bound Iterasi 1

\begin{tabular}{cccccccc}
\hline $\begin{array}{c}\text { Mesin / } \\
\text { Job }\end{array}$ & b1 & b2 & $\mathbf{b 3}$ & $\mathbf{b 4}$ & $\mathbf{b 5}$ & b6 & b7 \\
\hline M1 & 3276.71 & 3027.83 & 3027.83 & 3027.83 & 3027.83 & 3027.83 & 3027.83 \\
M2 & 813.61 & 931.13 & 590.85 & 1512.05 & 581.92 & 685.71 & 752.38 \\
M3 & 1794.65 & 1941.37 & 1590.50 & 2535.51 & 1581.30 & 1687.14 & 1755.59 \\
M4 & 18751.65 & 19293.31 & 18783.64 & 20085.75 & 18770.27 & 18906.85 & 19033.96 \\
M5 & 685.73 & 5432.54 & 983.98 & 12402.93 & 921.98 & 1499.41 & 2096.73 \\
M6 & 1296.73 & 6086.46 & 1611.43 & 13089.90 & 1548.74 & 2131.30 & 2733.06 \\
B & 18751.65 & 19293.31 & 18783.64 & 20085.75 & 18770.27 & 18906.85 & 19033.96 \\
\hline
\end{tabular}

TABEL 6. Perhitungan Branch and Bound Iterasi 2

\begin{tabular}{ccccccc}
\hline $\begin{array}{c}\text { Mesin / } \\
\text { Job }\end{array}$ & $\mathbf{b 2}$ & $\mathbf{b 3}$ & $\mathbf{b 4}$ & $\mathbf{b 5}$ & $\mathbf{b 6}$ & b7 \\
\hline M1 & 3276.71 & 3276.71 & 3276.71 & 3333.60 & 3276.71 & 3276.71 \\
M2 & 1320.73 & 980.44 & 1901.64 & 1028.12 & 1075.31 & 1141.98 \\
M3 & 2259.36 & 1908.48 & 2853.49 & 1951.72 & 2005.12 & 2073.57 \\
M4 & 19221.63 & 18711.96 & 20014.07 & 18702.40 & 18835.16 & 18930.27 \\
M5 & 5581.48 & 1132.91 & 12551.86 & 1074.04 & 1648.35 & 2213.66 \\
M6 & 6188.49 & 1713.46 & 13191.93 & 1650.77 & 2233.32 & 2803.08 \\
B & 19221.63 & 18711.96 & 20014.07 & 18702.40 & 18835.16 & 18930.27 \\
\hline
\end{tabular}

TABEL 7. Perhitungan Branch and Bound Iterasi 3

\begin{tabular}{cccccc}
\hline $\begin{array}{c}\text { Mesin / } \\
\text { Job }\end{array}$ & $\mathbf{b 2}$ & $\mathbf{b 3}$ & $\mathbf{b 4}$ & $\mathbf{b 6}$ & $\mathbf{b 7}$ \\
\hline M1 & 3333.60 & 3778.52 & 3333.60 & 3333.60 & 3333.60 \\
M2 & 1534.09 & 1636.95 & 2115.01 & 1288.67 & 1355.34 \\
M3 & 2398.09 & 2463.80 & 2992.22 & 2143.85 & 2212.30 \\
M4 & 18939.27 & 18453.95 & 19731.70 & 18552.80 & 18679.91 \\
M5 & 5733.80 & 1305.16 & 12704.19 & 1800.68 & 2397.99 \\
M6 & 6293.65 & 1818.62 & 13297.09 & 2338.48 & 2940.24 \\
B & 18939.27 & 18453.95 & 19731.70 & 18552.80 & 18679.91 \\
\hline
\end{tabular}


TABEL 8. Perhitungan Branch and Bound Iterasi 4

\begin{tabular}{ccccc}
\hline $\begin{array}{c}\text { Mesin / } \\
\text { Job }\end{array}$ & b2 & b4 & b6 & b7 \\
\hline M1 & 3778.5 & 3778.5 & 4301.6 & 3778.5 \\
M2 & 2142.6 & 2723.6 & 2418.5 & 1963.9 \\
M3 & 2905.7 & 3499.8 & 3146.1 & 2719.9 \\
M4 & 18637.7 & 19430.2 & 18275.7 & 18378.4 \\
M5 & 5911.2 & 12881.5 & 1998.0 & 2575.3 \\
M6 & 6404.6 & 13408.1 & 2449.4 & 3051.2 \\
B & 18637.7 & 19430.2 & 18275.7 & 18378.4 \\
\hline
\end{tabular}

TABEL 9. Perhitungan Branch and Bound Iterasi 5

\begin{tabular}{cccc}
\hline $\begin{array}{c}\text { Mesin / } \\
\text { Job }\end{array}$ & $\mathbf{b 2}$ & $\mathbf{b 4}$ & $\mathbf{b 7}$ \\
\hline M1 & 4301.61 & 4301.61 & 7587.44 \\
M2 & 2922.45 & 3503.37 & 6022.50 \\
M3 & 3559.71 & 4153.85 & 6547.15 \\
M4 & 18038.95 & 18831.39 & 17876.37 \\
M5 & 6179.04 & 13149.43 & 2922.40 \\
M6 & 6590.52 & 13593.96 & 3237.11 \\
B & 18038.95 & 18831.39 & 17876.37 \\
\hline
\end{tabular}

TABEL 10. Perhitungan Branch and Bound Iterasi 6

\begin{tabular}{ccc}
\hline $\begin{array}{c}\text { Mesin / } \\
\text { Job }\end{array}$ & $\mathbf{b 2}$ & $\mathbf{b 4}$ \\
\hline M1 & 14158.68 & 7587.44 \\
M2 & 13082.67 & 7105.56 \\
M3 & 13292.01 & 7526.43 \\
M4 & 17290.73 & 17901.39 \\
M5 & 6717.04 & 13538.70 \\
M6 & 6823.10 & 13826.53 \\
B & 17290.73 & 17901.39 \\
\hline
\end{tabular}

Hasil dari perolehan perhitungan tersebut, makespan pada penjadwalan produksi dapat selesai dengan waktu 15267.50 menit. Dengan demikian didapatkan urutan penjadwalan yaitu job 1-5-3-6-72-4. Selain itu, juga dapat dihitung nilai efisiensi makespan yaitu sebagai berikut.

$$
\begin{aligned}
\text { Efisiensi } & =\frac{\text { nilai makespan perusahaan-nilai makespan usulan }}{\text { nilai makespan perusahaan }} \times 100 \% \\
& =\frac{19278.13-17290.73}{19278.13} \times 100 \% \\
& =10.31 \%
\end{aligned}
$$

Diperoleh hasil nilai efisiensi makespan perusahaan sebesar $10.31 \%$.

\section{PENUTUP}

\section{Kesimpulan}

Kesimpulan yang diperoleh dari hasil penelitian ini adalah sebagai berikut.

a. Membangun model Integer Linear Programming pada penjadwalan produksi tipe flowshop ini telah diselesaikan.

b. Pada perhitungan Metode Branch and Bound diperoleh hasil nilai makespan sebesar 17290.73 menit dengan urutan penjadwalan job 1-5- 3-6-7-2-4, artinya urutan job yang dikerjakan yaitu 
desain PKF/01/12, PKF/P20/09, SOLID (2), PKF/P24/09, PKL/26/09, SOLID (1), dan $\mathrm{HYO} / 047$.

c. Program aplikasi yang telah dibuat memudahkan perusahaan dalam menyelesaikan masalah penjadwalan produksi.

d. Berdasarkan informasi yang telah diperoleh dari perusahaan, lamanya proses produksi/makespan yang dihasilkan sebesar 19278.13 menit dengan urutan job 1-2-3-4-5-6-7, atau dengan urutan desain PKF/01/12, SOLID (1), SOLID (2), HYO/047, PKF/P20/09, $\mathrm{PKF} / \mathrm{P} 24 / 09$, dan PKL/26/09. Hal tersebut menunjukkan bahwa penyelesaian pekerjaan lebih singkat menggunakan Metode Branch and Bound dengan selisih 1978.4 menit atau mempunyai nilai efiisiensi sebesar $10.31 \%$.

\section{DAFTAR PUSTAKA}

Baker K.R dan Trietsch D. 2009. Principles of Sequencing and Scheduling. American University of Armenia.

Mangngenre S, dkk. 2014. Penjadwalan Produksi Dengan Metode Branch And Bound Pada PT. XYZ. Universitas Hassanudin.

Mercado R.Z.R dan Bard J.F. 2013. A Branch And Bound Algorithm for Flowshop Scheduling with Setup Times. University of Texas. Austin.

Muhammad M dan Wulan E.R. 2017. Penjadwalan Optimal Tipe Produksi Flowshop Dua Tahap Menggunakan Metode Branch And Bound Dengan Memperhatikan Waktu Transportasi. ISSN : 2338-0896 Vol.2 No.1. Universitas Islam Negeri Sunan Gunung Djati. 